\title{
Chronic gastric dilatation in horses: diagnosis, treatment and feeding management - A survey of 20 clinical cases
}

\author{
Viola Bäuerlein', Ingrid Vervuert² and Monica Venner' \\ 'Equine Clinic, Destedt, Germany \\ ${ }^{2}$ Institute of Animal Nutrition, Nutrition Diseases and Dietetics, Faculty of Veterinary Medicine, University of Leipzig, Germany
}

\begin{abstract}
Summary: Chronic gastric dilatation is a rarely diagnosed disease of the horse. The objective of this report was to describe the clinical and ultrasonographic findings of 20 cases of chronic gastric dilatation in horses. Furthermore, horses' clinical history, signalment and clinical and gastroscopic findings were recorded. Medication, feeding management and outcome are presented. Inclusion criteria were: 1) Clinical signs of recurrent abdominal discomfort or resistance to the riders leg; 2a) Repeated ultrasonographic finding of an enlarged stomach (more than five intercostal spaces), or alternatively; $2 b$ ) Repeated gastroscopic finding of an impacted stomach in combination with a subsequent sonographical confirmation; 3a) No gastric emptying following 12 hours of starvation, or 3b) Emptying but repeated episodes of dilatation following normal feeding regime; 4) Exclusion of acute gastric impactions and other gastrointestinal disorders. All horses had shown one or several of the following symptoms: repeated signs of discomfort, recurrent mild or moderate acute colic, defensive reaction when fixing the girth or against the riders left leg, chronic weight loss, poor performance and more. With exception of the rectal examination, clinical and laboratory examination was not conclusive. 19 horses showed an enlarged stomach at initial sonography (range: six to eleven intercostal spaces). The initial examination in one horse referred to our clinic was merely by gastroscopy. Gastroscopy was performed in eleven cases. The horses were treated with metoclopramide hydrochloride ( $0.1-0.15 \mathrm{mg} / \mathrm{kg}$ twice daily p.o.) and feeding management was adapted according to nutritionist's or veterinarian's recommendations. The mean duration of treatment was 16 months at submission of the manuscript. No side effects were observed. Seventeen of the treated horses survived in the long term. One horse was euthanized 10 days after start of treatment with metoclopramide hydrochloride, at the request of the owner as he had noticed no clinical improvement in that period of time. Two horses were euthanized because of orthopedic problems. Fifteen horses showed complete, and four horses partial clinical improvement after treatment and feeding management was adapted. Metoclopramide hydrochloride seemed effective for the long-term treatment of chronic gastric dilatation. Long-term administration of metoclopramide hydrochloride could be an alternative to bethanechol. Further studies are needed to determine the exact pathophysiologic mechanisms of chronic gastric dilatation and to determine the exact diagnostic findings related to different disease states.
\end{abstract}

Keywords: horse, metoclopramide hydrochloride, chronic gastric dilatation, delayed gastric emptying, prokinetic drugs, gastroparesis.

Citation: Bäuerlein V., Vervuert I., Venner M. (2019) Chronic gastric dilatation in horses: diagnosis, treatment, feeding management - A survey of 20 clinical cases. Pferdeheilkunde 35, 129-137; DOI 10.21836/PEM20190205

Correspondence: PD Dr. Monica Venner PhD, Pferdeklinik Destedt, Trift 4, 38162 Destedt, Germany; mVenner@gmx.de

\section{Introduction}

Chronic gastric dilatation is a rarely diagnosed disease of the horse (Huskamp et al. 2010, Stroth and Belz 2014). It has previously been described in Europe but not in the US (Freeman 201 1). However, in 1945, Hutyra and Marek reported a chronic form of gastric overload in the horse that developed over a prolonged period of time, characterized by a recurrent gastric dilatation after unsuccessful emptying of the stomach. These authors concluded that in these patients the gastric wall constantly adapted to the condition and did not react with an hypertrophy.

The disease was reported in the German-speaking countries as CGID (Chronic Gastric Impaction and Dilatation) by Scheidemann and Huthmann (2011) as well as by Klier et al. (2017). Scheidemann and Huthmann (2011) defined it as a combination of gastric wall hypertrophy, gastric dilatation, and in some cases chronic mucosal ulcerations, which in turn indicate a long-term condition. The disease was usually associated with chronic gastric overload (Müller et al. 1995, May et al. 2012). The condition often progresses over several months or years until the stomach rupture finally occurred (May et al. 2012).
Regarding the etiology of chronic primary gastric dilatation in the horse only a few references can be found in the literature (Steinberg et al. 2007, Bird et al. 2012, Klier et al. 2017). Unfortunately, even post-mortem and histopathological examinations rarely provide a satisfactory explanation of the underlying cause (Klier et al. 2017). In a descriptive study, the etiology remained unclear in three of four clinical cases of CGID finally examined post mortem (Klier et al. 2017). In one case, mild vagal fiber loss was found in an unspecified region of the stomach wall associated with inflammatory changes. Neurological dysfunction was also listed by Müller et al. (1995) as a possible reason. Sutton (2014) suggested a primary interruption of the antro-pyloro-duodenally coordinated contraction leading to failure in gastric emptying and progressive expansion. Liver disease caused by Senecio jacobaea (ragwort) has been suspected as another reason for gastric impaction (Milne et al. 1990). Furthermore, large and indigestible objects that cannot be transported away via the pylorus, may have been the cause for accumulating fibrous materials and lead to impaction (Sutton 2014). One of the sources of origin for phytobezoars was described to be persimmon fruit (Hurtado et al. 2007). In addition, acquired or congenital obstruction and stenosis of the pylorus or polyps 
have been mentioned as mechanical impairments of gastric emptying (McGill and Bolton 1984, Church and Baker 1986, Venner 2004, Bezdekova and Hanak 2009, Furness et al. 2013). There are few data with regard to breed predisposition. However, progressive gastric dilatation and aggregation of feed components along the major curvature were described in Friesian horses, in which breed a primary neurological dysfunction was suspected (Sutton 2014). Winfield and Dechant (2015) also indicated that Friesians with primary stomach ruptures were over-represented in their normal clinic population and they reported that draft horses as well seemed to have a predisposition to stomach overload. In the case of Friesians, they suspected that this may have been due to increased pain tolerance, motility dysfunction or underlying tissue defects.

Early reports described the condition in the beginning as relatively asymptomatic (Huskamp et al. 2000, Steinberg et al. 2007), non-specific (Stroth and Belz 2014) and difficult to diagnose (Scheidemann and Huthmann 2011). The symptoms could vary, depending on the fill status of the stomach and can be similar to those of acute gastric overload (May et al. 2012). They increased with increasing filling of the stomach (Steinberg et al. 2007). Recurrent mild to moderate colics may have occured, often after feeding (Steinberg et al. 2007). Postprandial pain suggested the colic symptoms may have resulted from a gastric distension (McGill and Bolton 1984). In addition, feed intake may have been reduced (Steinberg et al. 2007).

Other symptoms of chronic gastric dilation included ventral abdominal distension, oedema, weight loss and spontaneous gastric rupture (Proudman and Baker 1994, May et al. 2012, Sutton 2014). Steinberg et al. (2007) described asymmetries at the height of the rib cage, visible from the caudal left side. Furthermore, eructation, recurrent colon constipation, flatulence, anorexia, loss of performance (Scheidemann and Huthmann 2011), salivation, bruxism and wasting (Steinberg et al. 2007, Klier et al. 2017) have also been described.

In some rare cases the diagnosis of a gastric impaction can be made at rectal examination if there is a filling content of more than 30-35 liters. In those patients a firm and convex mass can be palpated in the left abdomen. Usually the spleen is displaced medio-caudally in that cases (Hutyra et al. 1945, Huskamp et al. 2003). As a diagnostic tool transcutaneous ultrasonographic examination is a non-invasive (Lores et al. 2007), simple and rapid method of detecting chronic dilatation (Scheidemann and Huthmann 2011, Klier et al. 2017). In normally fed horses the stomach is visible on the left side of the abdomen between the 8th and 13th intercostal space (ICS) using a 3.5-MHz convex probe (Klohnen 2012, Lores et al. 2007) below an imaginary line from the elbow to the hip (Klohnen 2012, May et al. 2012). In adult healthy ponies, the hyperechoic line of the stomach can be seen between the 8th and 15th intercostal space over 4 to 7 ICS (5.1+/- 0.9) (Epstein et al. 2008). Content is not normally displayed, with the exception of fluid retention (Le Jeune and Whitcomb 2014). In the case of gastric emptying disorders, a hyper-echogenic material is described which produces an acoustic shadow in the lumen (Reef 1998). An illustration of a stomach wall displaced dorso-caudally is interpreted as stomach distension by Lores et al. (2017) and an enlarged radius of the curvature can also be seen (Le Jeune and Whitcomb 2014). Steinmann et al. (2007) describe a non-definable caudally thick-walled structure, with a hyperechogenic stretched line extending down, beyond which lies an area with acoustic shadow and with an absence of peristalsis. Reef (1998) also describes in the chronic gastric distension the hyperechogenic line of the stomach to be less circular than normal. When diagnosing chronic dilatation, dimensions are reported across at least five intercostal spaces (Reef 1998, Stroth and Belz 2014). To safely identify delayed gastric emptying, repeated examinations are recommended (Reef 1998).

The treatment of horses with chronic gastric distension is not clearly defined. Prokinetics are used to treat chronic gastric dilatation in horses and other animals. It is recommended to use them only in mild cases to avoid rupture (Müller et al. 1995). Prokinetics promote the transport of ingesta through the gastrointestinal tract, induce coordinated motility patterns (Dowling 1995) and are subdivided into those that promote motility due to their parasympathetic activity and those that inhibit sympathetic pathways (White and Dabareiner 1997). The benzamide metoclopramide acts as a 5-HT4 agonist and a 5-HT3 (Nolen-Walston et al. 2007) and dopamine (D2) antagonists and is used to promote gastrointestinal and small bowel motility (Wong et al. 2011). In human medicine, the drug is used for the treatment of diabetes-induced gastroparesis, despite possible side effects (Lee and Kuo 2010). Metoclopramide has both gastrointestinal and central nervous effects. In the upper gastrointestinal tract, it promotes acetylcholine release from the neurons and increases cholinergic receptor sensitivity to acetylcholine. In addition, it inhibits motility in the gastrointestinal tract due to its dopamine antagonizing action. Metoclopramide coordinates the motor activity of the oesophagus, stomach, pylorus and duodenum by increasing motility of the lower oesophagus and stomach and lowering motility in the duodenum and pylorus. This promotes gastric emptying and reduces oesophageal reflux (Dowling 1995). Okamura et al. (2009) described the use of orally administered metoclopramide hydrochloride in the horse at a dosage of $0.2 \mathrm{mg} /$ $\mathrm{kg}$ orally. Their results suggested that metoclopramide hydrochloride promotes, among other things, gastric emptying and jejunum motility. However, the drug crosses the blood-brain barrier and leads via a dopamine-antagonistic effect to an antiemetic effect and potential side effects (Dowling 1995). In the horse restlessness, excitement (Hunt and Gerring 1986), sweating, abdominal pain (Holcombe 2003), dystonic reactions (Doherty 2016) and extrapyramidal effects (Agass et al. 2017) have been described. Side effects are reported at a dosage of $0.25 \mathrm{mg} / \mathrm{kg} / \mathrm{h}$ continuous infusion (Hunt and Gerring 1986) or every six hours s.c. (Agass et al. 2017). In the pregnant mare metoclopramide hydrochloride should be used with caution. In human medicine, a contraindication in the first trimester of pregnancy is indicated by the manufacturers of the drug. However, studies on laboratory animals reveal no signs of teratogenic or fetotoxic effects (Dobler 2012).

In Germany metoclopramide is not listed in Regulation $37 / 2010$ (Pharmacologically active substances and maximum residue limits on food of animal origin). The use of metoclopramide is therefore per se not permitted in food-producing animals, but can be administered in equids for food chain (positive list), taking account of a waiting period of six months. 
There is actually no labeled specific equine metoclopramide preparation available. But according to the German Drug Law §56a para. (2) no. 2 and no. 3 AMG (Arzneimittelgesetz, 1976), there is the possibility to redefine the use in the horse. This allows the treatment with preparations labeled for other animal species or humans in a crisis situation (Dobler 2012).

The long-term prognosis of chronic gastric dilatation in horses is considered unfavourable (Steinberg et al. 2007, May et al. 2012, Furness et al. 2013, Klier et al. 2017). Scheidemann and Huthmann (2011) examined 17 horses with chronic gastric dilatation and increased gastric fill, 16 of which were euthanized due to the poor prognosis. Müller et al. (1995), on the other hand, suggested that patients with chronic gastric dilatation could tolerate and live with limited chronic enlargement.

In the present report, 20 cases with chronic gastric dilatation are presented, data were either collected retrospectively or through observation during therapy. The aim was to describe, in particular, the symptoms of chronic gastric dilatation and there evolution under the influence of therapy with orally administered metoclopramide hydrochloride, partly in combination with an adapted feeding regime, as well as to describe the prognosis with regard to survival and further equestrian use.

\section{Animals, material and methods}

Between 2011 and 2018, 20 horses aged six months to 20 years and a mean age of $12.4( \pm 5,5)$ years were examined. The age refers to the date of the initial examination. The oldest surviving horse is currently 25 years old. The breed distribution amounted to: 16 warmblood horses, one Friesian horse, one English thoroughbred, one Quarter horse and one Welsh pony. Thirteen of the horses were geldings, seven of the horses were mares.

Seventeen initial examinations took place in the Equine Clinic Destedt in Germany. Three horses were pre-examined in two other clinics. The first known reliable data are titled as "initial examination finding". Follow-up examinations were carried out in the Equine Clinic Destedt or in the home stables of the horses. The data was documented and retrieved using the Easyvet program. Furthermore, telephone and personal consultation with the horse owners took place. Collected data consisted of: history, signalment, symptoms, clinical, laboratory diagnostic, ultrasonographic and gastroscopic examination results, treatment, duration of treatment and clinical outcome. Long-term survival and clinical outcome were reviewed on the basis of follow-up or telephone inquiries.

Inclusion criteria in the clinical trial were:

1) Clinical signs of recurrent abdominal discomfort or resistance to the rider's leg

2a) Repeated ultrasonographic detection of an enlarged stomach (more than five intercostal spaces), or alternatively

2b) Repeated gastroscopic identification of an increased gastric fill with subsequent sonographic confirmation in the course of the study,

3a) Lack of gastric emptying following a twelve-hour starvation period (Fig. 1), or 3b) Physiological gastric emptying ability but repeated gastric dilatation under normal feeding regimens and

4) Exclusion of acute stomach overloads and other gastrointestinal diseases.

The diagnosis of chronic gastric dilatation was made on the basis of ultrasonographic examinations using a $3.5 \mathrm{MHz}$ convex probe and an ultrasound machine from Esaote Company (MyLab 30). In case of ambiguous interpretation, the uncertain intercostal spaces were not counted to avoid false positive measurements. The initial examination was carried out under normal feeding regime i.e. without starvation. In the following there was usually a starvation period of 12 hours between the first and second ultrasound scans. If the stomach did not empty after this fasting period, further periods of fasting were added and the ability to empty the stomach (amount of emptying) was documented. Follow-up examinations were performed in the clinic or in the home stable under the usual feeding regimes and compared with the results of the initial examination. Alternatively, owners were interviewed by phone about changes in the clinical symptoms they had previously observed.

For the gastroscopic examinations, a flexible, three-meterlong video endoscope from Storz Company (Tuttlingen, Germany) was used. Clinical and sonographic transabdominal examination were performed in all cases. Laboratory diagnostic and gastroscopic examinations were only performed in ten respectively eleven patients, often due to financial constraints. General clinical and follow-up examinations confirmed the diagnosis and excluded concurrent diseases.

After the diagnosis of chronic gastric dilatation, all horses were treated orally with metoclopramide hydrochloride $(0.1-$ $0.15 \mathrm{mg} / \mathrm{kg}$ twice daily, p.o.; MCP AL Tablets) by the owner. In horses presented on initial examination with severe chronic impaction or horses receiving mineral oil at initial presentation metoclopramide hydrochloride was administered parenterally (i.m.).

In seven cases, the feeding regime was changed by the nutritionist (Vervuert, I.). In further ten horses, a feeding plan was

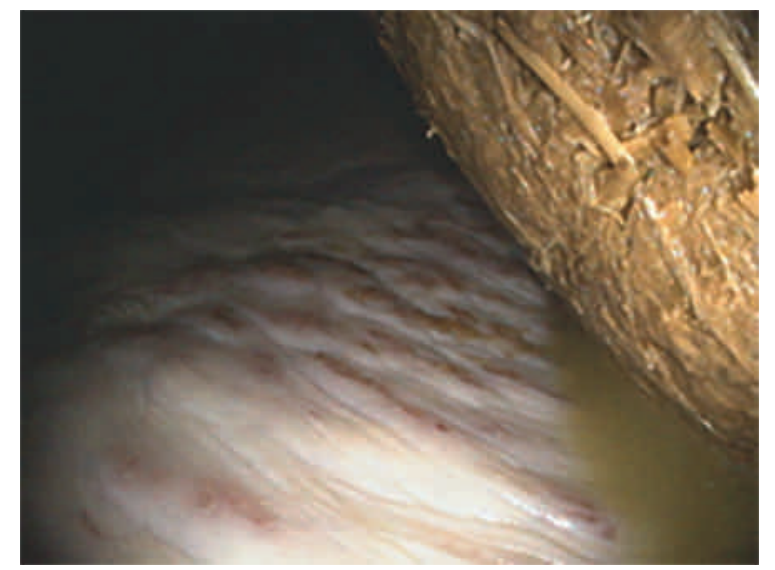

Fig. 1 Gastroscopic view of a stomach with large food ball after 24 hours of starving. Note the lesions of the squamous region. Gastroskopisches Bild einer erheblichen Futtermenge trotz 24 Stunden Hungerphase. Zu beachten sind die Läsionen der Schleimhaut der Pars non glandularis. 
adapted by the veterinarians of the Clinic Destedt based on the recommendations of the nutritionist:

- General information: Small meal sizes (provided over 4-6 meals per day). Use of hay nets (aim: increase feed intake time but provide a slow inflow of feed). Consideration of hygienic quality of feedstuffs. Partial or total replacement of hay by a grass meal slurry.

- Roughage: 24 hours pasture or alternatively restricted hay intake (1.5\% of BW) provided by a hay net (mesh sieve $<3 \mathrm{~cm}$ ). Hay from 1 st cut (or 2 nd leafy cuts). No straw bedding or straw feeding.

- Supplementary feed: Reduction in starch intake to avoid starch fermentation in the stomach. Feeding moderate amounts of a high-fat supplement feed (fat content: 8-10\%). Time lag between feeding and exercise and time lag between feeding and access to pasture to avoid undesirable fermentation processes in the stomach. Possible further additives: vegetable oil such as corn oil, amino acids (e.g. dried brewer's yeast).

- Promote adequate water intake: adequate water hygiene, unlimited access to water. In some cases higher water intake by hand-hot water provision or water provided in buckets. Some horse may increase water intake by adding table salt (up to $30-40 \mathrm{~g} / 500 \mathrm{~kg} /$ day).

\section{Results}

The symptoms shown by the horses were usually nonspecific. The owners reported one or more of the following symptoms listed here in decreasing prevalence (Table 1): recurrent colic, weight loss, poor riding performance (including inactive back activity, negative reaction to left-sided bending or left leg application), regurgitation, apathy/fatigue, eructation, teeth grinding, inappetence, postprandial colic, distended abdomen, increased lying, tense abdominal wall, temperament change, yawning, recurrent tachypnoea.

The clinical examination at first presentation, in all cases, apart from the rectal examination, revealed no particular findings indicating a gastric disorder. Here, six horses showed abnormalities that were probably directly associated with chronic

Table 1 Frequency of symptoms shown by 20 horses with chronic gastric impaction | Symptome der 20 Pferde mit chronisch dilatiertem Magen

\begin{tabular}{cc}
\hline Symptom & $\begin{array}{c}\text { Number of patients } \\
\text { showing symptoms }\end{array}$ \\
\hline recurrent colic & $\mathrm{n}=12$ \\
weight loss & $\mathrm{n}=8$ \\
poor performance & $\mathrm{n}=9$ \\
regurgitation & $\mathrm{n}=3$ \\
\hline apathy / fatigue & $\mathrm{n}=2$ \\
\hline $\begin{array}{c}\text { Eructation, teeth grinding, inappetence, } \\
\text { postprandial colic, distended abdo- } \\
\text { men, increased lying, tense abdominal } \\
\text { wall, yawning, recurrent tachypnoea }\end{array}$ & $\begin{array}{c}\text { (each symptom was pre- } \\
\text { sented by one patient) }\end{array}$ \\
\hline
\end{tabular}

gastric dilatation. Four times the spleen was found displaced caudally and/or medially, and five times a firm roundish structure was palpated in the left dorsal abdomen diagnosed as an enlarged stomach, which was confirmed at transabdominal sonography. Twelve horses were presented for acute colic in the clinic or at home and as part of the examination a nasogastric tube was inserted. A resistance could not be registered by pushing against the gastric contents during the advancement, despite parallel or subsequently sonographic observed gastric dilatation. One horse showed discomfort when inserting the tube and while adding fluid. Reflux was not observed in any of the horses. Gastric feed stuff could be siphoned off in only two of the horses.

On initial examination hematology was performed in ten horses and blood biochemistry in seven horses. In all of these investigations, there were no significant deviations from the norm.

Between two and eleven (mean 4.5) transabdominal sonographic examinations per horse were performed. In 19/20 horses, the stomach showed initial dimensions of six up to eleven intercostal spaces (mean 8.2). A horse was examined exclusively by gastroscopy in the initial examination, and incomplete gastric emptying was detected.

In the first follow-up after the onset of metoclopramide hydrochloride therapy, the measured gastric dimensions were zero (stomach non detectable; one horse) to eleven ICSs (mean 6.8). In five horses, no sonographic follow-up was performed after initiating metoclopramide hydrochloride therapy. All five horses improved clinically according to the owners and showed no further symptoms, which is why the owners renounced a follow-up. These five horses were still in treatment at the time the manuscript was submitted. There was a parallel feeding management adaptation according to veterinarian's recommendations in three of five of these horses.

Gastroscopic examinations were performed in eleven patients. Overall, between one and five examinations were performed per horse (mean 2.3). After twelve hours or prolonged starvation periods, gastroscopy still revealed accumulations of gastric contents in five horses. This prevented complete evaluation of the gastric mucosa even after air insufflation in three of these five horses.

Seven horses showed lesions of the gastric mucosa (Tab. 2). Four of these seven horses had lesions in the glandular region (EGGD), three of them in the form of low-grade non-hemorrhagic swelling, one had moderate, some hemorrhagic, some fibrino-suppurative hyperplastic folds. Mucosal lesions in the squamous region (EGSD) were diagnosed in four of the seven horses. There were lesions on the large curvature of scores 1 and 3 (score system ECEIM 0-4: each $\mathrm{n}=1)$ and on the lesser curvature lesions of scores 1, 2 and 3 (each $n=1)$.

In six horses, the stomach could not empty completely at all, despite a long period of fasting and sometimes multiple flushes. They underwent one to five starvation periods. In two of these horses, the duration of fasting was not known, as 
they were performed in other clinics. In nine other horses, the stomach was completely empty after a total of two to five starvation periods. In five other horses, a complete gastric emptying was observed after a single 12-hour starvation. All 14 horses with complete emptying of the stomach repeatedly showed gastric dilatations under normal feeding regimes at transabdominal sonography.

The metoclopramide hydrochloride treatment was carried out in seventeen horses as a permanent treatment. The therapy duration per horse currently amounts to four weeks to 54 months. The mean duration of treatment was 16 months when submitting the manuscript. In two horses, the therapy was temporarily interrupted, but then reinstated due to a subsequent clinical deterioration. After restarting the therapy, the symptoms of both horses improved, which is why it was decided to continue the therapy permanently.

In three additional horses either frequency of administration or drug dose was reduced during the course of therapy. At the beginning of the treatment period, these horses showed signs of oesophageal obstruction. In one of these horses signs were associated with oesophageal atonia.

Overall, a complete improvement in symptoms was seen under treatment in fifteen horses (three of these failed to empty the stomach completely during all observations).

Four other horses showed only some improvement of the symptoms. Three of these horses were unable to complete gastric emptying. Unlike all the other horses in the study, two of these three could no longer be used as riding and sport horses.

One horse was euthanized 10 days after start of treatment with metoclopramide hydrochloride, at the request of the owner as he noticed no clinical improvement in that period of time. Two more horses were euthanized due to orthopedic problems. Both showed a complete improvement in gastric symptoms up to that point in time.

\section{Discussion}

In the early stages of chronic gastric dilatation the symptoms are rather unspecific, which is why diagnosis is often difficult (Huskamp et al. 2000, Steinberg et al. 2007, Scheidemann and Huthmann 2011) and even with extreme gastric filling the symptoms may be minimal (Huskamp et al. 2000). All symptoms described by others have noted in our patients. Though not yet described were opposition to the riders leg impulses and at readjusting the girth. These more subtle signs might be induced by pain associated with increasing intraabdominal pressure that will increase consequently the intragastric pressure (Lorenzo-Figueras and Merrit 2002). Our patients, however, showed that chronic primary gastric dilatation should be considered as the differential diagnosis for many symptoms of mild abdominal pain.

Diagnosis is based on clinical and further investigations. Here the use of transabdominal sonography offers a non-invasive measurement of the expansion of the stomach. In cases of chronic gastric dilatations in horses, the physiological (Di Fillipo et al. 2016) and the pathological size of the stomach were determined at post-mortem examinations (Müller et al. 1995, Steinberg et al. 2007). Through transabdominal sonography, physiological and pathological stomach dimensions in horses can also be specified by defining the intercostal spaces (ICSs) in which the stomach outline can be seen. As such, Klier et al. (2017) directly compared gastric distention via transabdominal sonography (stomach outline was recognized from the 5 th to the 16 th ICS, so a total of 12 ICSs) with post-mortem examinations $(60 \times 60 \times 30 \mathrm{~cm})$ in one case. As far as we are aware, further direct comparisons of the dimension of the stomach at transabdominal sonography with exact measurements post mortem have not been described. The regular stated cut off value in the literature to differentiate between a physiological sized and a distended stomach is five ICSs (Reef 1998, Stroth and Belz 2014). In our case series the patients were presented with stomach dimensions above this cut off value associated with delayed gastric emptying. These observations, together with a history of reported symptoms of prolonged mild abdominal discomfort, led to the diagnosis of chronic gastric dilatation. We hypothesize, that in our patients the diagnosis was made at an earlier stage than in cases of previously published case reports, which showed more severe symptoms and probably a more chronic condition associated with a poorer prognosis (Müller 1995, Huskamp et al. 2000, Scheidemann and Huthmann 2011 , Klier et al. 2017).

Furthermore, eleven horses were examined by gastroscopy. During gastroscopy determination of the size of the stomach is not possible but the gastroscopy enables confirmation of the findings of the sonographic examination with regard to the stomach-fill after a fasting period, the evaluation of the content and the assessment of the gastric mucosa. We have decided to perform the initial gastroscopy after 12 hours of fasting, based on our observations of routine gastroscopic examinations of horses. Other authors often use a 16-hour fasting period (Vainio et al. 2011 ), which might prevent them to get information on delayed gastric emptying in some patients. In our experience horses generally show at that time a complete emptying of the stomach. This observation is in

Table 2 Gastroscopic finding of 11 of the 20 horses | Gastroskopische Befunde bei den 11 Pferden, die von den 20 mit chronischer Magendilatation endoskopiert wurden

\begin{tabular}{cccc}
\hline Gastric region & Number of patients with findings & Specific region Score & Number of patients with no findings \\
\hline Squamous region Larger curvature & $\mathrm{n}=2$ & Score: 1 and 3 & $\mathrm{n}=7$ \\
Squamous region Lesser curvature & $\mathrm{n}=3$ & Score: 1.2 and 3 & $\mathrm{n}=7$ \\
\hline Glandular region & $\mathrm{n}=4$ & & \\
\hline
\end{tabular}


contrast to that of Boswinkel et al. (2007). These authors noticed after 12 hours fasting, in 10 of the 15 horses fed with high fiber feed (dry matter $54 \%$ ) a considerable higher amount of ingesta during gastroscopy compared to the horses of the low fiber group, where only 3 of the 14 horses showed ingesta at gastroscopy. It was concluded that the lack of fiber eaten by horses in the low fiber-group may have led to this increased coprophagy and bedding eating. However, surprisingly, only very few reports describe the standardization of the required starvation period for gastroscopy in horses. There is an urgent need to standardize a starvation protocol in order to create a reproducible and comparable technique. Overall, gastroscopy revealed gastric emptying in five of 11 patients with abnormaly enlarged stomach diagnosed at sonography. The exact volume of gastric fill could not be determined in our patient population but has been described by other authors in the case of chronic gastric dilatations and overloads with total weights of 15 to $122 \mathrm{~kg}$ (Müller et al. 1995, Huskamp et al. 2000, Steinberg et al. 2007, Bird et al. 2012, Klier et al. 2017).

In this context, the three horses need to be mentioned, which showed one to several episodes of oesophageal obstruction-like symptoms. The first one was only six months old and suffered from both stomach dilatation as well as a partial oesophageal atonia. This horse showed several episodes of oesophogeal obstruction. The other two horses showed the symptoms after an attempt to reduce the frequency of drug administration from twice to once daily or in the first week of beginning the therapy. A possible explanation here is a backlog of gastric contents in the oesophagus during feed intake in these heavily prefilled stomachs. Due to the lack of endoscopic examination of the latter two horses, no association with gastric dilatation could be proven. However, all three patients improved under a regime of feed adjustment or change of feeding frequency together with drug therapy.

The cause of chronic gastric dilatation has not been conclusively clarified in our 20 cases. A mechanical cause in the sense of pyloric stenosis, which has been described previously as an 'outflow' obstruction of the stomach, could be ruled out in the 11 cases whose stomach's we endoscoped and could visualize the pylorus (Venner et al. 2004, Bezdekova et al. 2006, Bezdekova and Hanak 2009). Potential changes such as adhesions between the gastric wall and adjacent anatomical structures (Huskamp et al. 2000, Steinberg et al. 2007, Scheidemann and Huthmann 2011, May et al. 2012, Klier et al. 2017) as well as loss of (Klier et al. 2017) or increase in thickness of the musculature of the stomach wall (Huskamp et al. 2000, Steinberg et al. 2007, Scheidemann and Huthmann 2011, Bird et al. 2012) was not examined further in our patient population. For this a laparotomy or a laparoscopy would be needed for adequate diagnosis.

The most common treatment for gastric dilatation today is based on removal of gastric contents through naso-gastric flushing in standing horses (Vainio et al. 2011, Winter et al. 2012, Sutton 2014, Klier et al. 2017) or intraoperatively with additional reduction of the size of the stomach (Müller et al. 1995, Huskamp et al. 2010, Parker et al. 2011 ). Our experience is that rinsing food from the stomach of chron- ic cases often only has a short-term effect. Our experience is supported by the reports of other authors (Müller et al. 1995, Huskamp et al. 2000, Steinberg et al. 2007, Scheidemann and Huthmann 2011, May et al. 2012). It may be doubted that, unlike acute primary gastric overload, the one-time removal of gastric contents in a horse with chronic gastric dilatation will be unsuccessful in the long run, since recurrence is common, as we have shown. In this context, the administration of prokinetics is indicated. The literature mainly contains information on the parenteral administration of prokinetics. A recommendation aims at the subcutaneous (s.c.) administration of metoclopramide hypochloride $(0.02$ $0.1 \mathrm{mg} / \mathrm{kg}$ s.c.) every 4 to 12 hours (Sanchez et al. 2018). A study in Thoroughbred horses compared the repeated oral administration of metoclopramide $(0.2 \mathrm{mg} / \mathrm{kg}$ body weight) with other gastric emptying prokinetics by $13 \mathrm{CO}_{2}$ exhalation test (Okamura et al. 2009). Among other findings, the use of metoclopramide promoted gastric emptying. The authors observed mild depression only in one horse, but no other side effects. None of the 20 horses we described here, showed side effects during the treatment period.

In sports and show horses, both national or international regulations apply with regard to the use of doping-relevant substances. For this purpose, the owners of sport horses were informed accordingly. During the regular short-term interruption of the therapy for four days before and during competition, there was no recurrence of symptoms in any of the horses we treated.

Other prokinetic agents, such as the parasympathomimetic bethanechol were not used in our patients. Betanechol is to be administered orally three to four times daily (Sanchez et al. 2018). A long-term study comparing the effects and side effects of both prokinetic agents on gastric emptying in healthy horses and horses with chronic gastric dilatation would be of interest.

We can only speculate why most of the previous reports on chronic primary gastric dilatation in the horse came from the German-speaking countries. It is not clear whether the lack of international larger case series, is due to possible geographic or feeding influences or due to the still uncertain terminology. Furthermore differences in the forms of the disease between different breeds of horses cannot be excluded. However, chronic gastric dilatation may also be underdiagnosed, especially in the early stages. In our field study, there were horses with and without permanent gastric impaction, which may indicate differences in the chronicity. Further studies would be desirable in this context.

Overall, the chronic dilatation of the stomach in the horse is a rare condition with unclear aetiological and pathological genesis. However, the disease should be considered in differential diagnosis in horses presenting the unspecific symptoms described here. Transabdominal sonography provides a fast, non-invasive diagnostic option. However, possible limitations, such as the confusion with the left-sided dorsal colon position, should always be considered.

The enteral use of metoclopramide hydrochloride proved to be an effective and a promising therapeutic option. The adaptation of the feeding regime offers valuable support for the comfort of the affected horses. 
In our patient population the clinical improvement was clear, but the dimension of the stomach, which was determined sonographically, remained only slightly changed (mean 8.2 in the initial examination to mean 6.8 in the first reexamination after starting the metoclopramide hydrochloride therapy). Complete restoration is therefore unlikely. Nonetheless, the prognosis of survival and use as a riding and sport horse was not unfavorable. Horses owners, however, should be informed about the high cost and management effort, due to the long-term therapy.

\section{Statement of conflict of interest}

There is no conflict of interest. The authors of the article follow neither financial nor personal interests that may affect the results of the study and the article.

\section{References}

Agass R. F., Brennan M., Rendle D. I. (2017) Extrapyramidal side effects following subcutaneous metoclopramide injection for the treatment of post operative ileus. Equine Vet. Educ. 29, 564-568; DOI 10.1111/ eve. 12586

Bezdekova B., Hanak J. (2009) Pyloric stenoses in horses: a seven cases reports. Veterin. Medicina 54, 244-248; DOI 10.17221/1/2009-VETMED

Bezdekova B., Jahn P., Mezerova J. (2006) Pyloric ulceration and stenosis in a two-year-old thoroughbred filly: a case report. Veterin. Medicina, 51, 75-80; DOI 10.17221/5523-VETMED

Bird A. R., Knowles E. J., Sherlock C. E., Pearson G. R., Mair T. S. (2012) The clinical and pathological features of gastric impaction in twelve horses. Equine Vet. J. 44 (Supplements 43), 105-110; DOI 10.1111/i.2042-3306.2012.00674.x

Boswinkel M., Ellis A. D., Sloet van Oldruitenborgh-Oosterbaan M. M. (2007) The influence of low versus high fibre haylage diets in combination with training or pasture rest on equine gastric ulceration syndrome (EGUS). Pferdeheilkunde 23, 123-130; DOI 10.21836/PEM20070203

Church S., Baker J. R. (1986) Gastric retention associated with acquired pyloric stenosis in a gelding. Equine Vet. J. 18, 332-334; DOI 10.11 11/j.2042-3306.1986.tb03644.x

Di Filippo P. A., Coutinho I. S., Meireles M. A. D., Rodrigues A. B. F. $(2016)$ Resistance to rupture of the equine stomach. Pesqu. Vet. Brasil. 36, 1087-1090; DOI 10.1590/S0100-736X2016001100005

Dobler B. C. (2012) Medikamenteneinsatz bei der Stute während der Gravidität. Diss. Med. Vet. München, 228

Doherty T. (2016) Metoclopramide induced acute dystonic reactions in the horse. Equine Vet. Educ. 29, 569-571; DOI 10.1111/eve.12594

Dowling P. M. (1995) Prokinetic drugs: Metoclopramide and cisapride. Can. Vet. J. 36, 115-116

Epstein K., Short D., Parente E., Reef V., Southwood L. (2008) Gastrointestinal ultrasonography in normal adult ponies. Vet. Radiol. Ultrasound 49, 282-286; DOI 10.1111/j.1740-8261.2008.00367.x

Freeman D. E. (2011) Gastric impaction. Equine Vet. Educ. 23, 174176; DOI 10.11 11/j.2042-3292.2010.00206.x

Furness M. C., Snyman H. N., Abrahams M., Moore A., Vince A., Anderson M. E. (2013) Severe gastric impaction secondary to a gastric polyp in a horse. Can. Vet. J. 54, 979-982

Holcombe S. J. (2003) Monitoring Gastrointestinal Function in the Equine Intensive Care Unit. Clin. Tech. Equine Pract. 2, 156-164; DOI 10.1016/S15347516(03)00028-3
Hunt J. M., Gerring E. L. (1986) A preliminary study of the effects of metoclopramide on equine gut activity. Vet. Pharmacol. Therap. 9, 109-112; DOI 10.1111/j.1365-2885.1986.tb00019.x

Hurtado I. R., Stewart A., Pellegrini-Masini A. (2007) Successful treatment for a gastric persimmon bezoar in a pony using nasogastric lavage with a carbonated cola soft drink. Equine Vet. Educ. 19, 571-574, DOI 10.2746/095777307X215052

Huskamp B., Scheidemann W., Schusser G. F. (2000). Einige seltene Magen- und Duodenumerkrankungen beim erwachsenen Pferd: Zweiphasige Magenruptur, chronische Magendilatation, Duodenumdilatation mit Hypo- oder Aganglionose, Längsachsendrehung des Duodenum. Praktischer Tierarzt 82, 729-736

Huskamp B., Knopf N., Scharner D. (2003) Spezielle Untersuchungen Magen. In: Die rektale und die sonografische Untersuchung beim Kolikpferd, 2. korrigierte und erweiterte Auflage, was Verlag, München, 38

Hutyra F., Marek F., Manninger R. (1945) Chronische Magenerweiterung. In: Spezielle Pathologie und Therapie der Haustiere, 9. Aufl., Bd. 2, Gustav Fischer Verlag, Jena Kap.1: Krankheiten des Magens und des Darms. 95-96

Klier, J., Blutke A., Emrich D., Beckmann J., Wittschorek J., Medina-Torres C. E. (2017) Chronic gastric importation and dilatation in horses: clinical, diagnosis, treatment options and pathologic findings - A case series. Pferdeheilkunde 33, 438-446; DOI 10.21836/PEM20170503

Klohnen A. (2012) Abdominal ultrasonography in the equine patient with acute signs of colic. AAEP Proceedings 58, 11-18

Lee A., Kuo B. (2010) Metoclopramide in the treatment of diabetic gastroparesis. Expert Review of Endocrinology \& Metabolism 5, 653-662

Le Jeune S., Whitcomb M. B. (2014) Ultrasound of the equine acute abdomen. Vet. Clin. North Am. Equine Pract. 30, 353-381; DOI 10.1016/i.cveq.2014.04.011

Lorenzo-Figueras M., Merrit A. (2002) Effects of exercise on gastric volume and $\mathrm{pH}$ in the proximal portion of the stomach of horse. Am. J. Vet. Res. 63, 1481-1487; DOI 10.2460/ajvr.2002.63.1481

Lores M., Stryhn H., McDuffee L., Rose P., Muirhead T. (2007) Transcutaneous ultrasonographic evaluation of gastric distension with fluid in horses. Am. J. Vet. Res. 68, 153-157; DOI 10.2460/ajvr.68.2.153

May A., Venner M., Cavicchioli E., Gehlen H. (2012) Magenerkrankungen des Pferdes - Diagnostik und Therapie. Pferdeheilkunde 28, 388405; DOI 10.21836/PEM20120403

McGill C. A., Bolton J. R. (1984) Gastric retention associated with a pyloric mass in two horses. Aust. Vet. J. 61, 190-191; DOI 10.1111/ j.1751-0813.1984.tb07239.x

Milne E. M., Pogson D. M., Doxey D. L. (1990) Secondary gastric impaction associated with ragwort poisoning in three ponies. Vet. Rec. 126, 502-504

Müller, E., Donandt, D., Pingen, C., Zeitelhack, M. (1995) Beitrag zur chronischen primären Magendilatation beim Pferd - Ein Fallbericht. Pferdeheilkunde 11, 101-104

Nolen-Walston, R., Paxson J., Ramey D. W. (2007) Evidence-Based Gastrointestinal Medicine in Horses: It's Not About Your Gut Instincts. Vet. Clin. North Am Equine Pract. 23, 243-266; DOI 10.1016/j. cveq.2007.03.008

Okamura K., Sasaki N., Yamada M., Yamada H., Inokuma H. (2009) Effects of mosapride citrate, metoclopramide hydrochloride, lidocaine hydrochloride, and cisapride citrate on equine gastric emptying, small intestinal and caecal motility. Res. Vet. Sci. 86, 302-308; DOI 10.1016/j.rvsc.2008.07.008

Parker R. A., Barr E. D., Dixon P. M. (2011) Treatment of equine gastric impaction by gastrotomy. Equine Vet. Educ. 23, 169-173; DOI $10.1111 /$ i.2042-3292.2010.00165.x

Proudman C. J., Baker, S. J. (1994) Gastric disease in the adult horse: a clinical perspective. Equine Vet. Educ. 6, 178-184; DOI 10.1111/ j.2042-3292.1994.tb01 127.x 
Reef V. B. (1998) Adult abdominal ultrasonography. In: Equine Diagnostic Ultrasound. Philadelphia: W. B. Saunders Co., 277, 283, 331

Sanchez, L. C. (2018) Disorders of the Gastrointestinal System. In: Equine Internal Medicine, Fourth edition, Eds: Reed S. M., Bayly W. M. and Sellon D. C., St. Louis: Elsevier, pp 801, 808

Scheidemann W., Huthmann S. (2011) A contribution to disease of the equine stomach: chronic gastric impaction and dilatation. In: 4th European College of Equine Internal Medicine Congress Hannover 2011, proceedings pp. 45-46

Steinberg T., Hamann J., Deppenmeier S. (2007) Sekundäre chronische Magenobstipation durch idiopathische muskuläre lleumhypertrophie bei einem Pferd. Pferdeheilkunde 23, 587-592; DOI 10.21836/PEM20070603

Stroth C., Belz J.-P. (2014) Diagnostik der chronischen Magendilatation des Pferdes mittels transkutaner Abdominalsonographie und Gastroskopie. Prakt. Tierarzt 95, 2-4

Sutton D. (2014) Disorders of the equine stomach: what do we know and what do we still need to learn? European Veterinary Conference Voordjaarsdagen
Vainio K., Sykes B. W., Blikslager A. T. (2011) Primary gastric impaction in horses: A retrospective study of 20 cases (2005-2008). Equine Vet. Educ. 23, 186-190; DOI 10.11 11/j.2042-3292.2010.00153.x

Venner M. (2004) Pyloric stenosis: a rare disease with a typical anamnesis. Equine Vet. Educ. 16, 176-177; DOI 10.1111/j.20423292.2004.tb00291.x

White N. A., Dabareiner R. M. (1997) Treatment of impaction colics. Vet. Clin. North Am. Equine Pract. 13, 243-259; DOI 10.1016/S07490739(17)30239-0

Winfield L. S. , Dechant J. E. (2015) Primary gastric rupture in 47 horses (1995-201 1). Can. Vet. J. 56, 953-958

Winter J. C., Schmitz R. R., Gehlen H. (2012) Therapie der primären Magenüberladung des Pferdes. Pferdeheilkunde 28, 437-439; DOI 10.21836/PEM20120408

Wong D. M., Davis J. L. White N. A. (2011) Motility of the equine gastrointestinal tract: Physiology and pharmacotherapy. Equine Vet. Educ. 23, 88-100; DOI 10.1111/j.2042-3292.2010.00173.x 